\title{
Endoscopic Skull Base Surgery in the Pediatric Population
}

Tara $W u, M D^{1}$

Zachariah Chandy, $M D^{1, *}$

Elisabeth Ference, $M D M P H^{2}$

Jivianne T. Lee, $M D^{1}$

\author{
Address \\ *,1Department of Head and Neck Surgery, David Geffen School of Medicine at \\ University of California Los Angeles, 10833 Le Conte Ave, CHS 62-237, Los \\ Angeles, CA, 90095, USA \\ Email: zchandy@mednet.ucla.edu \\ ${ }^{2}$ Department of Otolaryngology-Head and Neck Surgery, Keck School of Medicine \\ of the University of Southern California, Los Angeles, CA, USA
}

Published online: 13 May 2021

(C) The Author(s) 2021. This article is an open access publication

This article is part of the Topical Collection on Pediatric Dermatology and Allergy

Keywords Expanded endoscopic sinus surgery $\cdot$ Endoscopic sinus surgery $\cdot$ Skull base surgery $\cdot$ Pediatrics

\begin{abstract}
Background Surgery is often indicated for definitive biopsy or as the primary treatment modality for pediatric skull base lesions. Traditionally, open surgical approaches were utilized to address pediatric skull base pathology. However recently, expanded endoscopic sinus surgery has been utilized as a minimally invasive approach to addressing skull base pathology in the pediatric population.

Purpose This review provides an overview of the current literature evaluating the unique anatomic challenges of the pediatric skull and the safety and efficacy of expanded skull base procedures in the pediatric population.

Findings The pediatric skull base and sinus anatomy is small and continues to develop throughout childhood leading to unique surgical challenges. Sphenoid sinus pneumatization and intercarotid distance at the skull base are two significant anatomic challenges to pediatric skull base surgery. Despite the distinctive anatomy challenges, recent studies demonstrate that the safety and efficacy of expanded endoscopic sinus surgery appear to be equivalent to traditional open surgical approaches.

Conclusion Expanded endoscopic sinus surgery in the pediatric population has similar efficacy and safety as the traditional open approaches.
\end{abstract}




\section{Introduction}

Pediatric skull base lesions are rare and account for approximately five percent of skull base lesions [1]. Skull base lesions in the pediatric population are varied with approximately half of the lesions being malignant [2]. In the anterior skull base, the most common lesions are encephaloceles, esthesioneuroblastomas, and fibrous dysplasia [3]. In the middle cranial fossae, possible lesions include craniopharyngiomas, pituitary adenomas, juvenile angiofibromas, hemangiomas, astrocytomas, malignant fibrous histiocytomas, and ameloblastoma. Surgery is often indicated for definitive biopsy or as the primary treatment modality for these pediatric skull base lesions.

Traditionally, transfacial and transcranial surgical approaches have been utilized for tumor extirpation. The approach can be challenging, as the surgeon may have to transgress vital anatomic structures and growth centers. Although traditional open surgery has proven effective, the morbidity of open surgery is significant [4]. The risks of open skull base surgery include alterations in craniofacial development, pituitary-hypothalamic axis abnormalities, injury to the optic nerve and optic chiasm, cerebrospinal fluid (CSF) leak, and meningitis $[1,3]$.

In the last two decades, endoscopic surgery has transformed skull base surgery in the pediatric population Minimally invasive endoscopic techniques have been employed for tumor extirpation. Endoscopic surgery allows access to midline and paramidline skull base tumors while avoiding transgression of growth centers [5]. In this review, we describe the current literature evaluating the unique anatomic challenges of the pediatric skull and the safety and efficacy of these expanded skull base procedures in the pediatric population.

\section{Anatomic considerations in the pediatric population}

The pediatric skull base and sinuses are small and develop at different rates during childhood [2]. The anterior skull base ossifies and attains its adult size at age 3, while the middle fossa and posterior fossa tend to reach adult size at age 10 . The variable growth of the skull base can lead to significant differences in anatomy between patients, making the surgical approaches more complex. In addition to the skull base, pediatric sinus development also ranges widely between age groups. The ethmoid sinuses are present at birth and continue to mature until age 17 [6]. However, the frontal sinuses are not present at birth and only begin to aerate and become visible between the ages of 4 and 12. At birth, the sphenoid sinuses are filled with bone, which slowly pneumatizes. The sphenoid sinuses continue to develop and aerate until age 10 to 14 [5]. The variable growth rate of the skull base and sinuses in pediatric patients combined with the tight working spaces of the pediatric skull pose several challenges to endoscopic sinus surgery.

Given the small working spaces in the pediatric population, adequate visualization can be a challenge. To optimize exposure, Khalili et al. suggested using a pediatric $2.7-\mathrm{mm}$ endoscope to begin the procedure until the bilateral maxillary sinuses, ethmoid sinuses, and sphenoid sinuses are open [7]. Once these sinuses are open, the group suggested switching over to a 4-mm endoscope given the superior visualization. They believed that using a smaller endoscope early reduces injury to the soft tissue of the midface and maxillary bone, which are important in midface development.

Additionally, the partial pneumatization of the sphenoid sinuses is a significant hindrance to endoscopic skull base surgery in the pediatric population. 
The incomplete pneumatization requires drilling through bone to approach skull base tumors and can limit visualization of the opticocarotid recess, raising concern for possible inadvertent injury to the internal carotid arteries and optic nerves. Additionally, the bone is often very vascular, which limits visualization and requires frequent suctioning [7]. However, the use of image-guided navigation and Doppler ultrasound has made it easier to locate key vasculature within the bone, which can significantly aid in dissection. Kuan et al. found no statistically significant association between the pattern of sphenoid pneumatization and the quality of resection, total operative time, presence of CSF leak, intraoperative blood loss, or length of hospital stay for pediatric patients who underwent skull base surgery for craniopharyngiomas [8]. They concluded that the degree of sphenoid sinus pneumatization, although a unique challenge in the pediatric population, does not appear to affect surgical outcomes and should not be a significant limiting factor in endoscopic skull base surgery.

Finally, another challenge to skull base surgery is the intercarotid distance at the skull base. Frequently to approach skull base tumors, dissection occurs between the internal carotid arteries. Therefore, the distance between the arteries can limit working distances and visualization. Figure 1 demonstrates the intercarotid distance of a 14-year-old male with a juvenile angiofibroma. Generally, a prohibitive intercarotid distance is believed to be $10 \mathrm{~mm}$ given the limitation in working space and concern for potential injury to the internal carotid arteries [9]. A study by Banu at al. analyzed magnetic resonance images (MRIs) of pediatric patients with skull base lesions. The study found the intercarotid distance was greater than $10 \mathrm{~mm}$ by 2 - to 4 -years-old [9]. This suggests that even in very young patients, the internal carotid distance is not a hindrance for endoscopic sinus surgery.

\section{Endoscopic approaches to the skull base}

Skull base surgeons are adapting the endoscopic techniques used in adult patients to approach skull base pathology in the pediatric population. The techniques are similar to what would be used in the adult population, albeit taking into account the unique anatomic considerations of the pediatric sinuses and skull base. Below are descriptions of the surgical approaches taken for
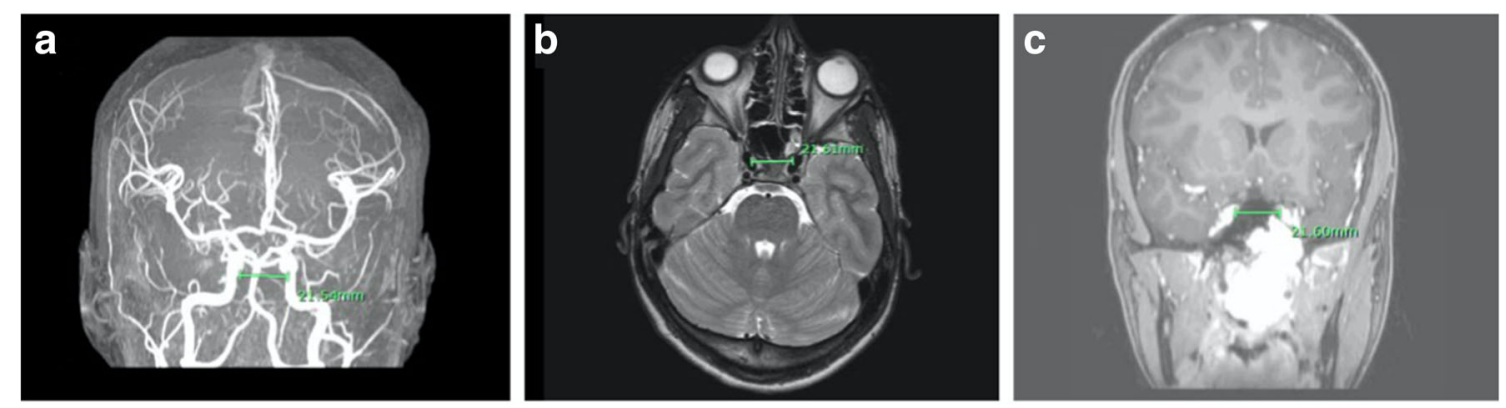

Fig. 1. Intercarotid distance in a 14-year-old male with a large juvenile nasopharyngeal angiofibroma, measured at the C4-5 bend on a 3D MRA, $\mathbf{b}$ axial T2, and $\mathbf{c}$ coronal T1 post contrast. 


\section{Table 1. Endoscopic skull base approaches}

\begin{tabular}{|c|c|c|}
\hline Approach & Anatomy accessible & Possible pathology \\
\hline Transellar & $\begin{array}{l}\text { - Sella and Suprasellar region } \\
\text { - Opticocarotid recess (optic nerve, optic chiasm, and internal } \\
\text { carotid artery) } \\
\text { - Cavernous Sinus }\end{array}$ & $\begin{array}{l}\text { - Pituitary tumors } \\
\text { - Craniopharyngiomas } \\
\text { - Hemangioma } \\
\text { - Juvenile angiofibroma } \\
\text { - Ameloblastoma } \\
\text { - Astrocytoma }\end{array}$ \\
\hline Transcribriform & $\begin{array}{l}\text { - Anterior cranial fossa from posterior wall of frontal sinus to } \\
\text { sphenoid sella } \\
\text { - Anterior and posterior ethmoid arteries } \\
\text { Encephalocele/meningoencephalocele } \\
\text { - Esthesioneuroblastoma } \\
\text { - Fibrous dysplasia }\end{array}$ & $\bullet$ \\
\hline Transclival & $\begin{array}{l}\text { - Clivus and vertebrobasilar junction } \\
\text { - Horizontal segment of internal carotid artery } \\
\text { - Vidian artery } \\
\text { - Cranial nerve six }\end{array}$ & $\begin{array}{l}\text { - Chordoma } \\
\text { - Basilar invagination } \\
\text { - } \\
\text { Encephalocele/meningoencephalocele }\end{array}$ \\
\hline
\end{tabular}

different locations in the pediatric skull base. Table 1 summarizes the name of the surgical approach, pertinent anatomy encountered, and examples of pathology that the approach has been utilized for. Figure 2 is a schematic illustrating the expanded endoscopic skull base approaches.

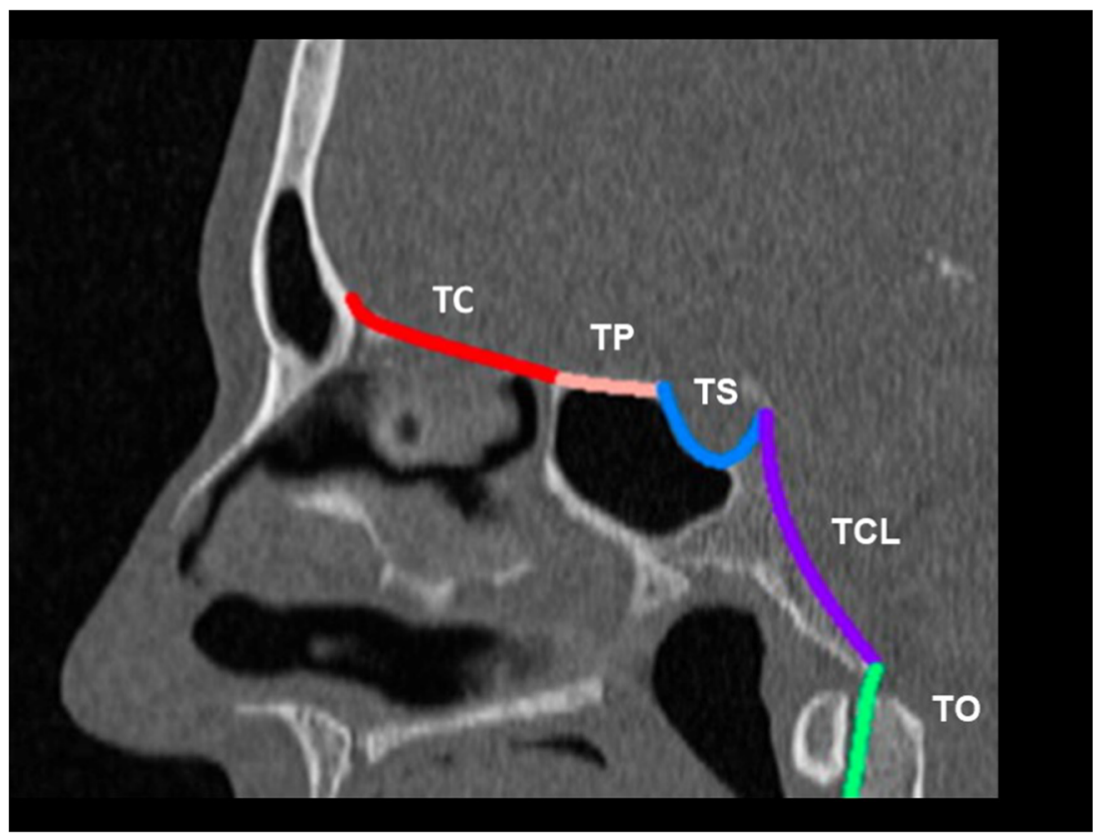

Fig. 2. Schematic illustrating expanded endoscopic skull base approaches. (TC: transcribriform, TP: transplanum, TS: transellar, TCL: transclival, T0: transodontoid). 


\section{A. Transellar}

The traditional skull base approach is transellar, which allows access to the sella of the sphenoid sinus and suprasellar region (Fig. 3). This approach can be used for lesions in the middle cranial fossae such as pituitary tumors and craniopharyngiomas. The transellar approach involves lateralization or removal of the middle turbinate of bilateral nasal cavities to allow the nasal endoscopes to be introduced [9]. Wide sphenoidotomies are performed extending from the lamina papyracea laterally to the planum tuberculum rostrally and the clivus caudally. This allows for visualization and access to the internal carotid arteries, optic nerves, planum sphenoidale, clivus, and medial cavernous sinus. If there is significant suprasellar extension of a lesion, the floor of the sphenoid sinus can be drilled back to the clivus [10]. This extension improves exposure in a rostro-caudal axis, which can be helpful for visualization of the lesion. The medial opticocarotid recess can be opened to expose the internal carotid artery. The optic nerve lies above the internal carotid artery. Avoidance of bipolar cautery in this region will limit damage to the optic nerves. For lesions involving the cavernous sinus, it is beneficial to use a Doppler ultrasound to locate the internal carotid artery [9]. This can aid in wider exposure while reducing risk of injury to the internal carotid artery.

\section{B. Transcribriform}

After a transellar approach has been performed, it can be combined with a transcribriform approach to access to the anterior skull base (Fig. 4). Following a transellar dissection with the planum sphenoidale visualized, dissection can

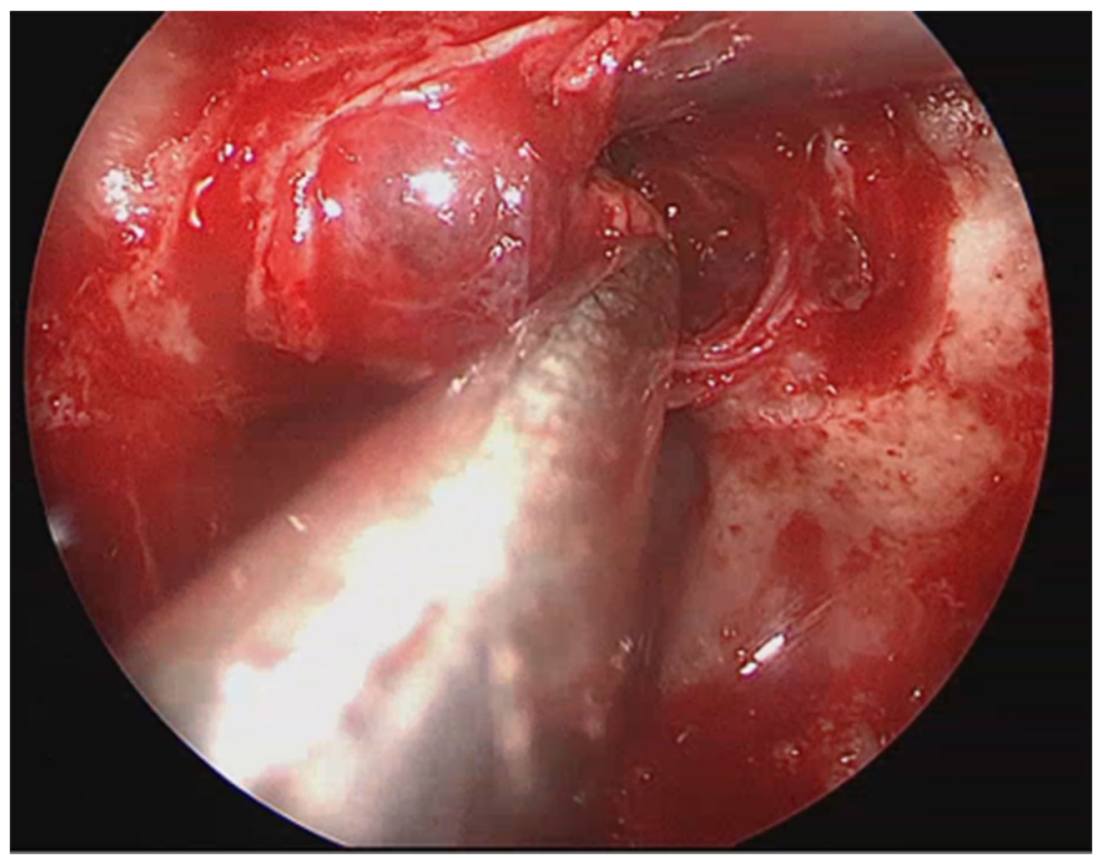

Fig. 3. Endoscopic photo illustrating transellar approach to pituitary adenoma. 


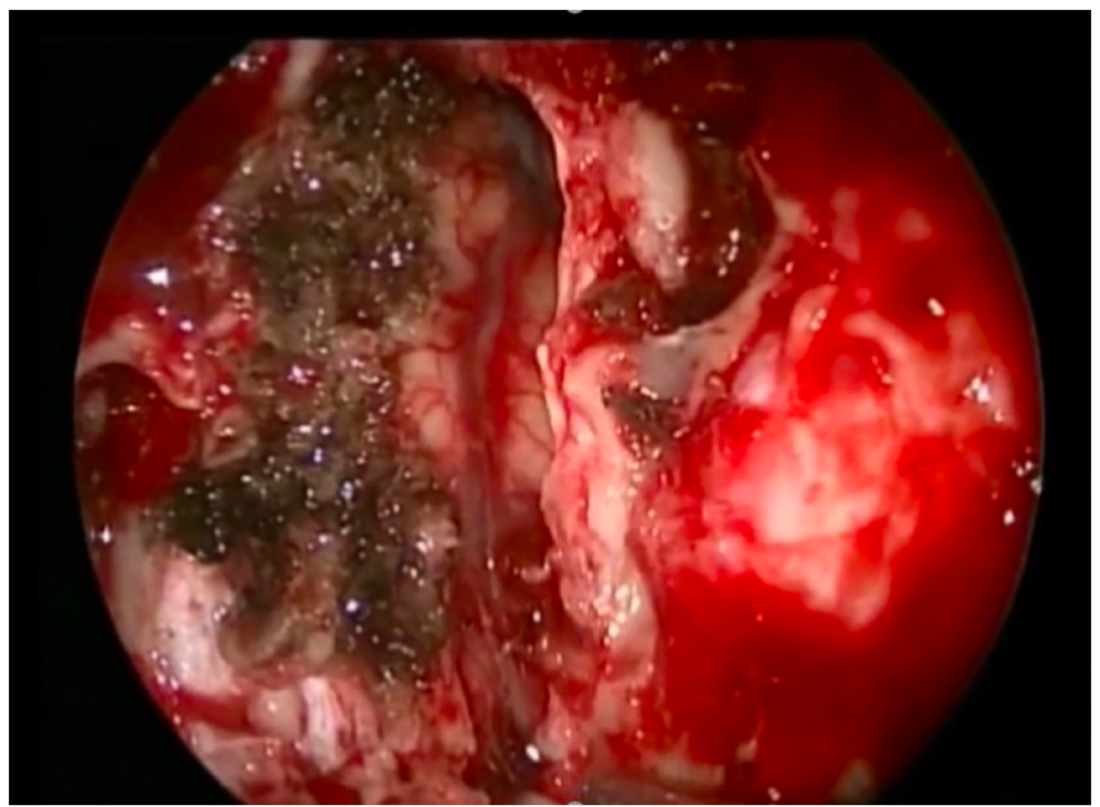

Fig. 4. Endoscopic photo illustrating transcribriform approach. The anterior skull base has been resected and frontal lobes can be visualized through the defect.

be carried anteriorly removing the ethmoid sinus partitions until the frontoethmoidal recess is seen [9]. If necessary, a Draf III procedure, which is removal of the frontal sinus floor, intersinus septum, and interfrontal septum, can provide additional access to the posterior wall of the frontal sinus. This approach allows wide access so that the cribiform plate and crista galli can be removed safely. The anterior and posterior ethmoid arteries can be ligated for tumor devascularization if necessary. If intradural dissection is warranted, the falx is approached laterally on either side to maintain the anterior falcine artery. The free edges of the falx are then cauterized and dissected to create one common intradural cavity.

\section{Transclival}

The transclival corridor dissection allows access to the vertebrobasillar junction, which can be helpful in approaching basilar invagination or additional lesions in proximity to the clivus. After a transellar approach has been performed, the floor of the sphenoid sinus is removed until it is flush with the clivus $[9,10]$. The clival bone can be removed with dissection carried to the vidian nerve, vidian artery, and horizontal portion of the internal carotid artery. To avoid injury to the internal carotid artery, the bone can be drilled from inferior to superior and medial to lateral with the vidian artery as the superior boundary of dissection [10]. If intradural dissection is warranted, full clivectomy can be performed. However, care must be taken when drilling as the sixth cranial nerve and the vertebrobasillar junction are in close proximity (Fig. 5). This endoscopic approach allows for improved visualization over the traditional transoral approach and may lead to less morbidity, for example, velopharyngeal incompetence or meningitis [10]. 


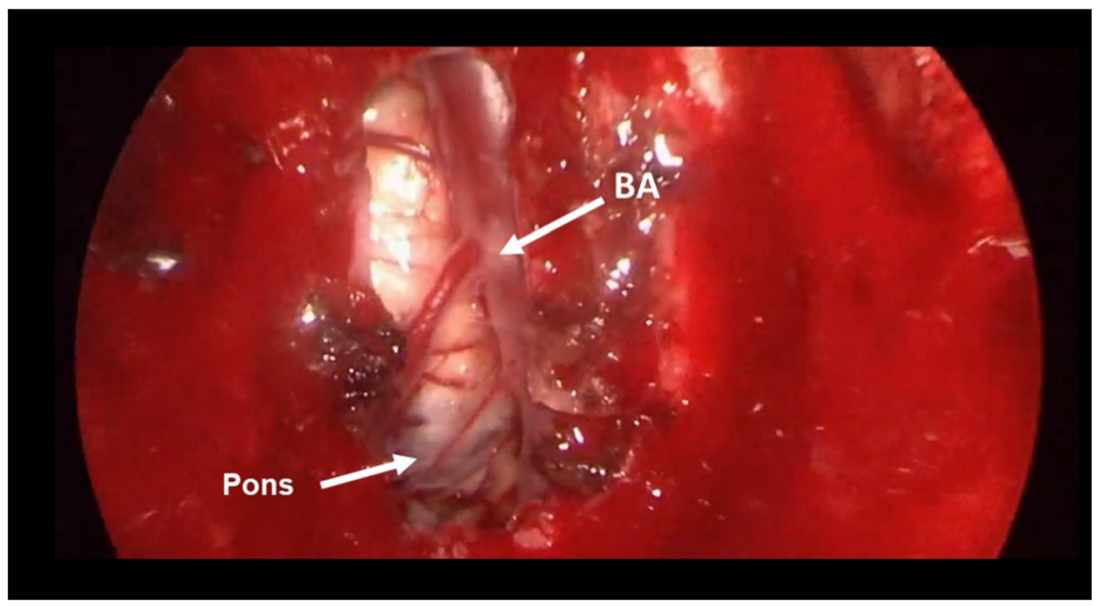

Fig. 5. Endoscopic photo illustrating transclival approach. The basilar artery and pons can be visualized through the bony window.

In addition to planning the surgical approach for skull base lesions, it is imperative to consider the reconstructive options for the resulting skull base defects. Reconstruction of skull base defects provides a barrier between the sinonasal and intracranial compartments, which reduces the risk of CSF leak and meningitis. The reconstruction technique chosen is based on the defect size, presence of CSF leak, intensity of CSF flow, and presence of intracranial hypertension.

If the skull base defect is less than $1 \mathrm{~cm}$ and there is no or minimal CSF leak noted following tumor extirpation, the defect can be closed with a free graft such as mucosa, cartilage, bone, muscle, or fat $[9,11]$.

For larger skull base defects with moderate to high CSF leak, a vascularized flap, such a nasal septal flap (NSF) or turbinate flap, is indicated. The NSF is dependable and safe option for skull base repair and has become widely used in skull base surgery in the adult population. Although the efficacy of NSFs has been well established in adults, the appropriateness of the NSF has been called into question for large skull base defects in the pediatric population. A main concern is the potential limitations in length and width a NSF can provide for large skull base defects given the relatively small nasal septal size in the pediatric population. Current literature suggests that NSFs are appropriate for sellar and suprasellar defects, but may not provide adequate coverage for transclival and transcribriform defects. Shah et al. compared the potential maximal NSF length and width to the potential skull base defects of fifty pediatric patients based on radioanatomic measurements [12]. For transellar approaches, the NSF length and width were found to provide adequate coverage of the skull base defects for all pediatric age groups. For a transcribriform approach, the nasal septal length was determined to be adequate coverage only for patients over the age of 9 . For a transclival approach, the NSF length was not adequate for coverage in any age group. Ghosh et al. analyzed the radioanatomic measurements of sixteen pediatric patients who underwent NSF reconstruction of suprasellar defects and determined that the NSF had appropriate length for patients less than 6years-old, between 6 - and 10-years-old, and over the age of 10 [13]. The study 
reviewed the outcomes of the same sixteen patients after surgery and found that all sixteen patients did have adequate NSF coverage. Of note, one of the patients had a postoperative CSF leak. However, it was believed to be secondary to technical error rather than inadequate coverage.

With very large intradural defects, a "gasket seal closure" can be utilized. Autologous fascia lata is placed over the intradural defect, while a piece of Medpor is placed in a countersunk fashion to hold the fascia lata in place. This allows a watertight closure. This closure is followed by a NSF [9]. When there is concern for significant intracranial hypertension, such as with an encephalocele or meningoencephalocele, a lumbar drain can be placed and removed in the postoperative period [9].

\section{Outcomes}

When considering outcomes of the expanded endoscopic surgical techniques, it is important to understand outcomes following traditional open surgical approaches for context. Common complications for open skull base surgery include pituitary-hypothalamic axis abnormalities, injury to the optic nerve and optic chiasm, CSF leak, and meningitis [1,3]. Gil et al. analyzed outcomes of sixty-seven pediatric patients who underwent open surgical approaches to skull base tumors [4]. Seventy-three percent of patients had total gross tumor resection. Twenty-seven percent of patients underwent subtotal resection. No postoperative CSF leaks or intracranial infections occurred. The overall complication rate was $32 \%$ with a breakdown as follows: wound infection $2 \%$, carotid artery injury $2 \%$, visual field deficits $2 \%$, hemiparesis $3 \%$, and panhypopituitarism $9 \%$.

Several retrospective studies have demonstrated similar safety and efficacy of expanded endoscopic surgical approaches when compared to traditional open approaches in the pediatric population [10, 14-18]. In one of the largest retrospective reviews, Chivukula et al. studied one hundred and thirty-three pediatric who underwent expanded endoscopic sinus surgery [14]. Fifty-seven percent of patients had gross total resection of tumor. Twenty-eight percent of patients had subtotal resection, with eighteen percent going on to receive adjuvant therapy such as radiation or chemotherapy. Twelve percent had recurrences within the first 2 years. Postoperative infections included meningitis (4\%), sinus infections (6\%), and abscesses (2\%). Other postoperative complications included CSF leak (11\%), hematoma $(2 \%)$, diabetes insipidus $(15 \%)$, and permanent cranial nerve deficit $(2 \%)$. Of the pathological lesions, juvenile angiofibromas and craniopharyngiomas were associated with postoperative complications attributed to vascularity and proximity to vital structures. For gross total resection of lesions, CSF leak and postoperative infection rates were comparable or slightly better than historical rates from open procedures.

A second retrospective study demonstrated similar safety and efficacy of expanded endoscopic skull base surgery. Kassam et al. published the outcomes of twenty-five pediatric patients who underwent expanded endoscopic skull base procedures [10]. Pathology was varied and included microadenoma of the pituitary, transcribriform meningoencephaloce, clival chordoma, juvenile angiofibroma involving the clivus, germinoma, and B-cell lymphoma of 
sphenoid. Of patients with benign disease, total gross resection was achieved in $80 \%$ of cases. Several patients underwent subtotal resection to avoid inadvertent injury to adjacent vital structures such as the pituitary stalk and optic nerve. Of the six patients with malignancy, five underwent biopsy with subsequent chemotherapy and/or radiation without recurrence. One patient underwent an open anterior skull base procedure for a neuroendocrine tumor of anterior skull base and orbit. CSF leaks were seen in eight percent of the patients postoperatively, which were repaired with a second surgery without complications. Although the complication rates were not insignificant, they appear comparable with traditional open procedures at this time. As endoscopic techniques advance and surgeons become more facile with techniques in the pediatric population, the morbidity associated with skull base surgery is likely to decrease.

\section{Midfacial development after endoscopic sinus surgery}

Craniofacial development can be altered with traditional open transfacial and transcranial approaches. There is similar concern regarding potential stunting of midfacial development following expanded endoscopic sinus surgery due to alternations in nasal growth zones. Several studies analyzing functional endoscopic sinus surgery in the pediatric population have demonstrated no significant change in facial growth [19-21]. Parasher et al. compared the midfacial growth of pediatric patients who underwent endoscopic sinus surgery to traditional open approaches for craniopharyngioma with panhypopituitarism with at least 3 years follow-up [22]. Patients with panhypopituitarism were chosen to reduce the risk of confounding from hormonal differences. Using cephalometric analysis of MRIs at 3 years post procedure, the study found no significant difference in midfacial growth between the endoscopic approach and the open approach. Chen et al. also sought to analyze the midface changes from expanded endoscopic sinus surgery in the pediatric population [23]. The study analyzed pediatrics patients who underwent expanded skull base surgery with a variety of pathologies. They compared cephalometric analysis of the patients who underwent surgery compared to normative data at 5-year follow-up and found no difference in growth. This suggests that over a 5-year period, there was no significant difference in midfacial growth compared to normal controls. When comparing growth by gender, pathology of tumor, use of nasoseptal flap, and radiation, no significant associations with growth were noted. These two studies suggest that following expanded endoscopic skull base surgery, midfacial growth may not be affected.

\section{Conclusion}

Endoscopic skull base surgery is revolutionizing skull base surgery in the pediatric population. In the past, transfacial and transcranial open surgical approaches were utilized, which can alter craniofacial development. With the advent of endoscopic skull base surgery, minimally invasive techniques can be utilized, which have the similar efficacy and safety as traditional approaches. As endoscopic techniques advance and surgeons become more familiar with 
techniques in the pediatric population, the morbidity associated with skull base surgery may decrease.

\section{Declarations}

\section{Conflict of interest}

Tara Wu declares that she has no conflict of interest. Zachariah Chandy declares that she has no conflict of interest. Elisabeth Ference declares that she has no conflict of interest. Jivianne T. Lee declares that she has no conflict of interest.

Open Access This article is licensed under a Creative Commons Attribution 4.0 International License, which permits use, sharing, adaptation, distribution and reproduction in any medium or format, as long as you give appropriate credit to the original author(s) and the source, provide a link to the Creative Commons licence, and indicate if changes were made. The images or other third party material in this article are included in the article's Creative Commons licence, unless indicated otherwise in a credit line to the material. If material is not included in the article's Creative Commons licence and your intended use is not permitted by statutory regulation or exceeds the permitted use, you will need to obtain permission directly from the copyright holder. To view a copy of this licence, visit http://creativecommons.org/licenses/by/4.0/.

\section{References}

1. Lopresti MA, Sellin JN, Demonte F. Developmental considerations in pediatric skull base surgery. J Neurol Surg B. 2018;79:3-12.

2. Duek I, Fliss DM. Unique considerations in pediatric skull base surgery. Oper Tech Otolaryngol. 2019;30:28.

3. Tsai EC, Santoreneos S, Rutka JT. Tumors of the skull base in children: review of tumor types and management strategies. Neurosurg Focus. 2002;12:e1.

4. Gil Z, Constantini S, Spektor S, Abergel A, Khafif A, Beni-Adani $\mathrm{L}$, et al. Skull base approaches in the pediatric population. Head Neck. 2005;27:682-9.

5. Banu MA, Guerrero-Maldonado A, Mccrea HJ, GarciaNavarro V, Souweidane MM, Anand VK, et al. Impact of skull base development on endonasal endoscopic surgical corridors: clinical article. J Neurosurg Pediatr. 2014; 13:155-69.

6. Kobets A, Ammar A, Dowling K, Cohen A, Goodrich J. The limits of endoscopic endonasal approaches in young children: a review. Childs Nerv Syst. 2020;36:263-71.

7. Khalili S, Palmer JN, Adappa ND. The expanded endonasal approach for the treatment of intracranial skull base disease in the pediatric population. Curr Opin Otolaryngol Head Neck Surg. 2015;23:65-70.

8. Kuan EC, Kaufman AC, Lerner D, Kohanski MA, Tong CCL, Tajudeen BA, et al. Lack of sphenoid pneumatization does not affect endoscopic endonasal pediatric skull base surgery outcomes. Laryngoscope. 2019;129:832-6.

9. Banu MA, Rathman A, Patel KS, Souweidane MM, Anand VK, Greenfield JP, et al. Corridor-based endonasal endoscopic surgery for pediatric skull base pathology with detailed radioanatomic measurements. Neurosurgery. 2014;10:273-93.

10. Kassam A, Thomas AJ, Snyderman C, Carrau R, Gardner P, Mintz A, et al. Fully endoscopic expanded endonasal approach treating skull base lesions in pediatric patients. J Neurosurg. 2007;106:75-86.

11. Rastatter JC, Snyderman CH, Gardner PA, Alden TD, Tyler-Kabara E. Endoscopic endonasal surgery for sinonasal and skull base lesions in the pediatric population. Otolaryngol Clin N Am. 2015;48:79-99.

12. Shah RN, Surowitz JB, Patel MR, Huang BY, Snyderman CH, Carrau RL, et al. Endoscopic pedicled nasoseptal flap reconstruction for pediatric skull base defects. Laryngoscope. 2009;119:1067-75.

13. Ghosh A, Hatten K, Learned KO, Rizzi MD, Lee JY, Storm PB, et al. Pediatric nasoseptal flap reconstruction for suprasellar approaches. Laryngoscope. 2015;125:2451-6.

14. Chivukula S, Koutourousiou M, Snyderman $\mathrm{CH}$, Fernandez-Miranda JC, Gardner PAT-KE. Endoscopic endonasal skull base surgery in the pediatric population clinical article. J Neurosurg Pediatr. 2013;11:22741. 
15. Brockmeyer D, Gruber DP, Haller J, Shelton C, Walker ML. Pediatric skull base surgery. Pediatr Neurosurg Karger Publishers. 2003;38:9-15.

16. Quon JL, Kim LH, Hwang PH, Patel ZM, Grant GA, Cheshier SH, et al. Transnasal endoscopic approach for pediatric skull base lesions: a case series. J Neurosurg Pediatr. 2019;14:1-12.

17. Locatelli D, Rampa F, Acchiardi I, Bignami M, Pistochini A, Castelnuovo P. Endoscopic endonasal approaches to anterior skull base defects in pediatric patients. Childs Nerv Syst. 2006;22:1411-8.

18. Castelnuovo P, Bignami M, Pistochini A, Battaglia P, DI Locatelli D. Endoscopic endonasal management of encephaloceles in children: an eight-year experience. Int J Pediatr Otorhinolaryngol. 2009;73:1132-6.

19. Senior B, Wirtschafter A, Mai C, Becker C, Belenky W. Quantitative impact of pediatric sinus surgery on facial growth. Laryngoscope. 2000;110:1866-70.

20. Bothwell M, Piccirillo JF, Lusk RP, Ridenour BD. Longterm outcome of facial growth after functional endoscopic sinus surgery. Otolaryngol Head Neck Surg. 2002;126:628-34.
21. Van Peteghem A, Clement PAR. Influence of extensive functional endoscopic sinus surgery (FESS) on facial growth in children with cystic fibrosis. Int J Pediatr Otorhinolaryngol. 2006;70:1407-13.

22. Parasher AK, Lerner DK, Glicksman JT, Storm PB, Lee JYK, Vossough A, et al. The impact of expanded endonasal skull base surgery on midfacial growth in pediatric patients. Laryngoscope. 2020;130:338-42.

23. Chen W, Gardner PA, Branstetter BF, Liu SD, Chang YF, Snyderman $\mathrm{CH}$, et al. Long-term impact of pediatric endoscopic endonasal skull base surgery on midface growth. J Neurosurg Pediatr. 2019;23:523-30.

\section{Publisher's Note}

Springer Nature remains neutral with regard to jurisdictional claims in published maps and institutional affiliations. 